University of Nebraska - Lincoln

DigitalCommons@University of Nebraska - Lincoln

Faculty Publications: Agricultural Economics

Agricultural Economics Department

2018

\title{
A Re-Examination of Multistage Economies in Hog Farming
}

Joshua D. Parcel

lowa State University, joshparcel@gmail.com

John R. Schroeter

lowa State University, johns@iastate.edu

Azzeddine M. Azzam

University of Nebraska-Lincoln, Aazzam1@unl.edu

Follow this and additional works at: https://digitalcommons.unl.edu/ageconfacpub

Parcel, Joshua D.; Schroeter, John R.; and Azzam, Azzeddine M., "A Re-Examination of Multistage Economies in Hog Farming" (2018). Faculty Publications: Agricultural Economics. 159.

https://digitalcommons.unl.edu/ageconfacpub/159

This Article is brought to you for free and open access by the Agricultural Economics Department at DigitalCommons@University of Nebraska - Lincoln. It has been accepted for inclusion in Faculty Publications: Agricultural Economics by an authorized administrator of DigitalCommons@University of Nebraska - Lincoln. 
Joshua D. Parcel' / John R. Schroeter ${ }^{1}$ / Azzeddine M Azzam²

\title{
A Re-Examination of Multistage Economies in Hog Farming
}

\author{
${ }^{1}$ Department of Economics, lowa State University, lowa, United States of America, E-mail: joshparcel@gmail.com, \\ johns@iastate.edu \\ ${ }^{2}$ Department of Agricultural Economics, University of Nebraska - Lincoln, Lincoln, USA, E-mail: aazzam@unlnotes.unl.edu
}

\begin{abstract}
:
Current trends in the structure of hog production in the U.S. are toward facilities that are not only larger, but also more likely to be specialized, carrying out only some of the vertically linked phases of production in the same facility. This paper investigates the cost efficiency incentives for these changes by estimating a multistage cost function for hog production. Data are from the Hog Production Practices and Costs portion of the USDA's 2004 Agricultural Resource Management Survey.
\end{abstract}

Keywords: ARMS data, hog production, scale and scope economies, vertical integration

DOI: 10.1515/jafio-2017-0033

Notes: This project received financial support from the National Research Initiative Competitive Grants Program (Markets and Trade area), CSREES/USDA, proposal No. 2007-04495. The opinions expressed herein are those of the authors and do not necessarily reflect the views of CSREES or USDA. The authors gratefully acknowledge helpful communications with Robert Dubman, Nigel Key, and William McBride.

The structure of U.S. hog production has undergone significant changes in the past two decades. Key and McBride (2007) document these changes with statistics drawn from three surveys of U.S. hog producers associated with the USDA's Agricultural Resource Management Survey (ARMS) in 1998 and 2004, and with ARMS' predecessor, USDA's Farm Costs and Returns Survey (FCRS), in 1992. From 1992 to 2004 the number of hog farms fell by over $70 \%$ while the nation's hog/pig inventory remained fairly stable, implying a substantial increase in the average size of operations. In fact, "large" hog operations, those with 2,000 head or more, accounted for only $30 \%$ of the hog/pig inventory in 1992 but nearly $80 \%$ by 2004 . Changes have also occurred in the vertical organization of the industry. The traditional "farrow-to-finish" operation included all of the phases of hog production: breeding and gestation, farrowing, nursery, and growing/finishing. Today, operations that specialize in just a subset of these vertically linked stages are becoming more prevalent. Farrow-to-feeder operations, for example, perform the first three phases of production, turning out an intermediate output, "feeder pigs." ${ }^{1}$ Feeder-to-finish operations perform just the growing/finishing phase in which feeder pigs are acquired from outside suppliers and grown to market weight. The traditional farrow-to-finish producers accounted for $54 \%$ of all hog farms in 1992, but only $31 \%$ in 2004 . Over the same period, the share of specialized feeder-to-finish operations among hog farms grew from $19 \%$ to $40 \%{ }^{2}$

While there may be more than one driving force behind these structural changes, cost efficiency considerations undoubtedly play a role. ${ }^{3}$ Any empirical exploration of the industry's cost structure should recognize the fact that production occurs in vertically-linked stages that can be accomplished in separate specialized operations or combined into integrated operations in which the intermediate product, feeder pigs, are transferred internally. One previous study has taken this approach. Azzam and Skinner (2007) used data on farm-level costs and outputs collected from a non-random sample of hog farmers in Iowa and Nebraska in surveys conducted between 1988 and 1996 to estimate a multistage cost function for hog production. Their results provided evidence of initial economies of scale in operations specializing in either the farrow-to-feeder or feeder-to-finish stages of production. However, they also found evidence of vertical economies of scope; that is, evidence of a cost advantage to integrating both vertical stages of production into a single operation as opposed to producing the same stage-specific output quantities in separate disintegrated operations. This latter finding suggests that the traditional, relatively small-scale, farrow-to-finish operation can, by combining both stages of production in a single farm, achieve cost savings that could make it competitive with large-scale specialized operations. This is a significant and intriguing result because it suggests that there must be other factors, beyond cost efficiency issues, contributing to the decline of traditional hog farms. ${ }^{4}$ 
The Azzam and Skinner paper was an important contribution as the first study of vertical cost relationships in agricultural production, let alone hog production, but it is not without shortcomings. ${ }^{5}$ It focused on hog producers in only two states and relied on data from surveys that predate much of the recent change in industry structure. For this reason, even the largest hog farms reflected in the Azzam and Skinner data were not particularly large by today's standards. In this article, we redo the analysis of Azzam and Skinner using a data set that is more recent, includes more observations, and is more representative of both the geographic and establishment size distributions of the current industry. Our data are taken from the Hogs Production Practices and Costs and Returns Report of the 2004 ARMS. The ARMS survey includes information on a sample of hog farms chosen, using a complex sampling method, to be representative of the target population of all U.S. hog farms with 25 or more hogs at any time during the year. Nineteen states are represented in the sample. In our use of the ARMS data to estimate a multistage cost function for hog production, we include both fully-integrated (farrow-to-finish) and completely specialized (either farrow-to-feeder or feeder-to-finish) operations. But we also develop methods for utilizing information about the cost function that is reflected in the performance of numerous "partially-integrated" hog farms that operate on both stages of production but also engage in either the purchase or sale of the intermediate input, feeder pigs.

The remainder of this article is organized as follows. The next section reviews some basic multiproduct cost concepts, their extension to the case of multistage production, and their application to the hog industry. Section three presents some details of the 2004 ARMS survey on hog production and explains the classification of hog farms comprising our sample. Details of the measurement of stage-specific outputs are relegated to an appendix. Section four introduces the empirical cost function and derives the corresponding expressions for the relevant multistage cost relations. The complex survey method used to collect the ARMS data has implications about estimation of regression parameters and standard errors. These are discussed in section five. Section six presents the results with respect to multistage economies of scale and scope in the hog industry. A final section offers concluding remarks.

\section{Multiproduct and Multistage Cost Concepts and the Hog Industry}

The development of concepts for characterizing the cost structures of multiproduct firms began with several papers by Baumol (1977) and Panzar and Willig (1975); 1977; 1981 and is summarized by Bailey and Friedlaender (1982). Kaserman and Mayo (1991) adapted multiproduct cost concepts to the case of "multistage" firms engaged in production at more than one vertically-related stage. In this section, we present a brief summary of methods for measuring economies of scale and scope in a multiproduct setting, and the modifications needed to apply these concepts to a multistage setting.

To begin with a familiar context, that of a single-product firm, a useful measure of scale economies is provided by the reciprocal of the elasticity of cost with respect to output:

$$
E S\left(y^{0}\right)=\left(\left.\frac{d \ln C(y)}{d \ln y}\right|_{y=y^{0}}\right)^{-1}
$$

where $y$ is the quantity of output and $C(y)$ is the cost of producing the output. If $E S\left(y^{0}\right)$ is greater (less) than one, cost increases less (more) than proportionately when output increases from $y=y^{0}$, and economies (diseconomies) of scale are said to exist.

Now consider a multiproduct firm producing $n$ outputs in quantities denoted $y_{i}$ for products indexed $i=$ $1,2, \ldots, n$. Let $C(y)$ now denote the total cost of producing $y$, an $n$-tuple of outputs with $i^{\text {th }}$ element $y_{i}$. While there is generally no unique and economically-meaningful way to apportion the costs of joint production of a particular output vector among the individual products, one can define, for each product $i$, an incremental cost function as

$$
C_{i}\left(y_{i}, y_{-i}\right)=C(y)-C\left(y_{1}, \ldots, y_{i-1}, 0, y_{i+1}, \ldots, y_{n}\right),
$$

where $y_{-i}$ is an $n-1$-tuple of outputs consisting of all elements of $y$ except $y_{i}$. Defined in this way, $C_{i}\left(y_{i}, y_{-i}\right)$ is the added cost of producing the $i^{\text {th }}$ product, in quantity $y_{i}$, given production of the other $n-1$ products in quantities given by the elements of $y_{-i}$. Using the "reciprocal-cost-elasticity" device again, as in the case of a single product firm, product $i$-specific scale economies $\left(P E S_{i}\right)$ for the multiproduct firm can then be defined as

$$
\operatorname{PES}_{i}\left(y^{0}\right)=\left(\left.\frac{\partial \ln C_{i}\left(y_{i}, y_{-i}\right)}{\partial \ln y_{i}}\right|_{y=y^{0}}\right)^{-1}
$$


If $P E S_{i}\left(y^{0}\right)$ is greater (less) than one at output vector $y^{0}$, the incremental cost of producing the $i^{\text {th }}$ output increases less (more) than proportionately with an increase in $y_{i}$ when holding the outputs of other products fixed, and product $i$-specific scale economies (diseconomies) are said to exist.

The concept of product specific scale economies is sufficient to describe cost efficiency in a multiproduct setting if all but one output is fixed. How cost responds to proportional increases in all outputs simultaneously is captured by the concept of ray scale economies:

$$
\operatorname{RSE}\left(y^{0}\right)=\left(\left.\frac{d \ln C\left(t y^{0}\right)}{d \ln t}\right|_{t=1}\right)^{-1} .
$$

This measure describes the response of cost to the kind of simultaneous increases in all outputs that amount to a movement along a ray from the origin in output space. If $R S E\left(y^{0}\right)>1$, for example, then starting from output vector $y^{0}$, a $10 \%$ increase in all outputs would result, to a first approximation, in less than a $10 \%$ increase in cost. In this case, we would say that the technology is characterized by multiproduct economies of scale at $y^{0}$.

One final concept useful for characterizing the cost structure of multiproduct firms is that of scope economies, measuring the increase or decrease in cost that results from producing multiple outputs jointly rather than separately. For a firm producing two outputs, for example, scope economies at $y^{0}$ are defined as

$$
\operatorname{SCPE}\left(y^{0}\right)=\frac{C\left(y_{1}^{0}, 0\right)+C\left(0, y_{2}^{0}\right)-C\left(y^{0}\right)}{C\left(y^{0}\right)} .
$$

When scope economies are greater than zero at $y^{0}$, the cost of joint production of the elements of output vector $y^{0}$ is less than the combined costs of production of each of the components separately.

Multistage production differs from multiproduct production in that the multiple stage structure requires intermediate inputs - outputs from upstream stages - for use in downstream stages. The measures of economies for multiproduct production can, nonetheless, be applied to measurement of cost efficiency in multistage firms with only slight modification. The change that is needed is an adjustment to the cost function to net out any expenditure on purchase of intermediate inputs produced in upstream stages. Without this adjustment, the cost of an intermediate input would be double counted when the costs of disintegrated upstream and downstream firms are summed for comparison with the cost of an integrated firm producing the same end product. ${ }^{6}$ The need to correct for these expenditures only arises with firms that purchase some or all of their intermediate input needs; fully integrated firms require no such adjustment to their cost functions. Hereafter, the " $C(\cdot)^{\text {" }}$ notation denotes a multistage cost function and it should be understood that the function incorporates this correction for expenditures on intermediate inputs.

Our multistage view of the hog industry recognizes two separable stages of production: farrow-to-feeder and feeder-to-finish, the upstream and downstream stages, respectively. The intermediate input, feeder pigs, refers to pigs weighing approximately 50 pounds. Output at the farrow-to-feeder stage $(F A R)$ and output at the feeder-to-finish stage (FIN) are measured in hundred-weight gain. ${ }^{7}$ In this context, vertical scope economies indicate whether it is cheaper to grow feeder pigs and finished hogs in a vertically integrated farrow-to-finish operation, or separately using disintegrated farrow-to-feeder and feeder-to-finish operations. The vertical scope economies measure for the hog industry is an application of eq. (3):

$$
\operatorname{VSE}\left(F A R^{0}, F I N^{0}\right)=\frac{C\left(F A R^{0}, 0\right)+C\left(0, F I N^{0}\right)-C\left(F A R^{0}, F I N^{0}\right)}{C\left(F A R^{0}, F I N^{0}\right)} .
$$

Stage-specific scale economies for the farrow-to-feeder stage $\left(S E S_{1}\right)$ and the feeder-to-finish stage $\left(S E S_{2}\right)$ are applications of the product-specific scale economy measure in eq. (1):

$$
S E S_{1}\left(F A R^{0}, F I N^{0}\right)=\left(\left.\frac{\partial \ln C_{1}(F A R, F I N)}{\partial \ln F A R}\right|_{(F A R, F I N)=\left(F A R^{0}, F I N^{0}\right)}\right)^{-1}
$$

and

$$
S E S_{2}\left(F A R^{0}, F I N^{0}\right)=\left(\left.\frac{\partial \ln C_{2}(F A R, F I N)}{\partial \ln F I N}\right|_{(F A R, F I N)=\left(F A R^{0}, F I N^{0}\right)}\right)^{-1}
$$

where $C_{1}(\cdot)$ and $C_{2}(\cdot)$ are the incremental cost functions for the feeder pig and finished hog outputs, respectively. Finally, multistage scale economies for the two-stage hog industry emerge as an application of the ray scale economy concept in eq. (2): 


$$
\begin{aligned}
\operatorname{MSE}\left(F A R^{0}, F I N^{0}\right) & =\left(\left.\frac{d \ln C\left(t \cdot F A R^{0}, t \cdot F I N^{0}\right)}{d \ln t}\right|_{t=1}\right)^{-1} \\
& =\frac{C\left(F A R^{0}, F I N^{0}\right)}{d C\left(t \cdot F A R^{0}, t \cdot F I N^{0}\right) /\left.d t\right|_{t=1}}
\end{aligned}
$$

\section{Data, the ARMS Survey, and Hog Farm Classification}

In our assessment of multistage economies in the hog industry, we use the farm level hog production cost data from the Hogs Production Practices and Costs and Returns Report portion of the 2004 Agricultural Resource Management Survey (ARMS), Phase III, jointly sponsored by the Economic Research Service (ERS) and the National Agricultural Statistics Service (NASS) of the U.S. Department of Agriculture. The survey provides a unique opportunity for estimation of production cost in the U.S. hog industry as ARMS involves a nationally representative sample and contains information on field-level farm practices, the economics of the operation, and corresponding household characteristics (USDA/ERS 2009).

The data set includes 1198 observations and presents information relevant to cost function estimation in the form of data that are directly collected through a survey questionnaire and variables that are calculated based on survey responses. For the purposes of this study, the relevant information for each sampled producer consists of: the general nature of the producer's operation; the total cost of the farm's pig/hog operation; stocks and flows of pigs/hogs at various stages of development, measured by both head count and total livestock weight; feed costs; and hired labor wage rates. ${ }^{8}$ The information about the nature of production operations included a classification into six producer "types:" farrow-to-finish, farrow-to-feeder, feeder-to-finish, farrow-to-weanling, weanling-to-feeder, and mixed producer. Because our model of the hog industry accounts for only two stages of production, sampled farms were used only if they engaged exclusively in the production of feeder pigs and/or market hogs. Those operations purchasing/placing or selling/removing weanlings, and those reporting sales of boars and sows (often classified as "mixed producers") were excluded. ${ }^{9}$ The glossary of Key and McBride (2007) provides definitions of the six producer types but, in general, the survey classified producers according to the nature of the preponderance of their operations. Thus, a farm classified as "farrow-to-finish" in the survey might actually engage in limited purchases or sales of feeder pigs as well as sales of market hogs. To more accurately reflect the nature of hog production operations, the sampled farms that exclusively produced feeder pigs and/or market hogs were reclassified into one of five categories: fully integrated farrow-to-finish, completely specialized farrow-to-feeder, completely specialized feeder-to-finish, partially integrated forward, and partially integrated backward.

The fully integrated farrow-to-finish farms operate by farrowing out pigs, growing them to feeder pig weight, then transferring all of the resulting feeder pigs internally to the farm's feeder-to-finish stage, and eventually selling market hogs as the finished product. No additional feeder pigs are purchased for input into the feeder-to-finish stage nor are any sold as output. In the completely specialized farrow-to-feeder operations, pigs are farrowed out and grown to feeder pig weight. Once this weight is reached, all feeder pigs are sold/removed with none retained for feeding to market weight. In completely specialized feeder-to-finish operations, feeder pigs are purchased/placed, fed to market weight, and sold/removed as market hogs.

There are two farm types characterized as "partially integrated." In partially integrated backward operations, pigs are farrowed out and grown to feeder pig size before transfer to the operation's feeder-to-finish stage and eventual sale as market hogs. However, in these operations, the internally produced feeder pigs are supplemented by market purchases of feeder pigs that become additional inputs to the feeder-to-finish stage. Figure 1 illustrates the process for these farms. Those farms operating under the partially integrated forward system, illustrated in Figure 2, farrow out pigs and raise them to feeder pig weight. Once reaching feeder pig weight, some are transferred internally to the farm's feeder-to-finish stage while others are sold on the market as feeder pigs. ${ }^{10}$

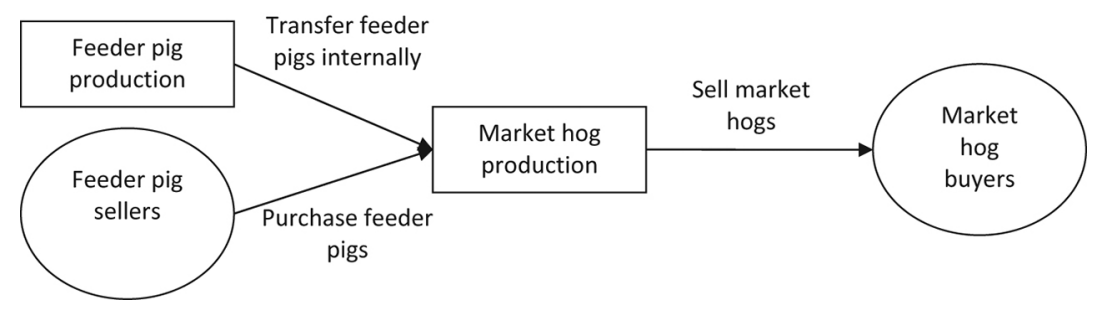


Figure 1: Partially-integrated backward operation.

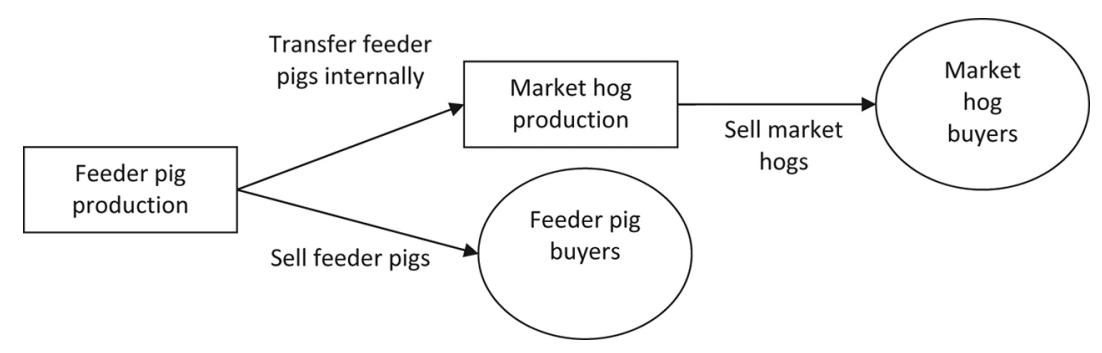

Figure 2: Partially-integrated forward operation.

Not all of the 1198 sampled farms fell into one of these five categories. Those that did were subjected to a series of logical data checks that resulted in the removal of an additional fifty-three records for which there were inconsistencies. ${ }^{11}$ After screening the sample, 746 observations remained for estimating the multistage cost function. The initial results of estimation identified two outliers that were subsequently excluded from the final sample. ${ }^{12}$

\section{Empirical Cost Function}

In order to estimate multistage scale and scope economies, a multistage cost function must first be specified and estimated. The functional form chosen for the cost function is quadratic in output with stage specific intercepts, as used in Azzam and Skinner's (2007) previous work on multistage economies in the hog industry and in Kwoka (2002) work on the electric power industry. One advantage of the quadratic form over the also common translog form is that it is easily able to handle zero output for any stage which occurs naturally with farms specializing in a single stage of production (Kwoka 2002). Specifically, the multistage cost function is ${ }^{13}$

$$
\begin{gathered}
C=\beta_{0}+\beta_{1} D F A R+\beta_{2} D F I N+\beta_{3} F A R+\beta_{4} F I N+\beta_{5} F^{2}+\beta_{6} F^{2} N^{2}+ \\
\beta_{7} \text { FAR } x \text { FIN }+\beta_{8} \text { PFEED } x \text { FAR }+\beta_{9} \text { PFEED } x \text { FIN }+ \\
\beta_{10} \text { WAGExFAR }+\beta_{11} \text { WAGE } x \text { FIN }+\varepsilon
\end{gathered}
$$

The dependent variable in multistage cost function estimation should be an appropriate cost measure, net of expenditure on purchases of the intermediate input. In our application, $C$ is defined as the year's reported total cost for the farm's hog operation, including both operating costs and allocated overhead, net of expenditure on purchases of feeder pigs. ${ }^{14}$ The independent variables FAR and FIN are the stage-specific output measures defined as hundred weight gain during the year at the farrow-to-feeder and feeder-to-finish stages of production, respectively. ${ }^{15} D F A R$ is an indicator variable of operation at the farrow-to-feeder stage. Likewise, DFIN is an indicator of operation at the feeder-to-finish stage. Independent variables measuring input prices for feed $(P F E E D)$ and labor (WAGE) are included in interaction terms with the output measures. ${ }^{16} \mathcal{E}$ is a random error term.

The measures of multistage scale and scope economies can be evaluated by substituting eq. (8) into eqs. (4) through (7). From eq. (4), vertical scope economies are given by

$$
\operatorname{VSE}(F A R, F I N)=\frac{\beta_{0}-\beta_{7} F A R x F I N}{C(F A R, F I N)}
$$

From eq. (5), stage-specific scale economies for the farrow-to-feeder stage are given by

$$
\operatorname{SES}_{1}\left(F A R^{0}, F I N^{0}\right)=\left(\left.\frac{\partial C_{1}(F A R, F I N)}{\partial F A R} \cdot \frac{F A R}{C_{1}(F A R, F I N)}\right|_{(F A R, F I N)=\left(F A R^{0}, F I N^{0}\right)}\right)^{-1}
$$

where $C_{1}(\cdot)$ is the incremental cost function for the farrow-to-feeder stage ${ }^{17}$ :

$$
\begin{aligned}
C_{1}(F A R, F I N)= & \beta_{0}(1-D F I N)+\beta_{1}+ \\
& \left(\beta_{3}+\beta_{7} F I N+\beta_{8} P F E E D+\beta_{10} W A G E\right) \cdot F A R+\beta_{5} F A R^{2},
\end{aligned}
$$


for $F A R>0$. Carrying out the differentiation in (10) and dropping the " 0 " superscripts:

$$
\begin{gathered}
\operatorname{SES}_{1}(F A R, F I N)= \\
\beta_{0}(1-D F I N)+\beta_{1}+\beta_{3} F A R+\beta_{5} F A R^{2}+\beta_{7} F A R \times F I N+ \\
\beta_{8} \text { PFEED } x \text { FAR }+\beta_{10} \text { WAGE } x \text { FAR } \\
\beta_{3} \text { FAR }+2 \cdot \beta_{5} F^{2}+\beta_{7} \text { FAR } x \text { FIN }+\beta_{8} \text { PFEED } x \text { FAR }+\beta_{10} \text { WAGE } x \text { FAR }
\end{gathered}
$$

for $F A R>0$. Likewise, from eq. (6), stage-specific scale economies for the feeder-to-finish stage are given by:

$$
\begin{gathered}
\operatorname{SES}_{2}(F A R, F I N)= \\
\beta_{0}(1-D F A R)+\beta_{2}+\beta_{4} F I N+\beta_{6} F_{I N}^{2}+\beta_{7} F A R \times F I N+ \\
\beta_{9} \text { PFEED } x \text { FIN }+\beta_{11} W A G E x F I N \\
\beta_{4} F I N+2 \cdot \beta_{6} F^{2} I^{2}+\beta_{7} F A R \times F I N+\beta_{9} P F E E D x F I N+\beta_{11} W A G E x F I N
\end{gathered}
$$

for FIN $>0$. Finally, using eq. (7) and recognizing that

$$
\left.\frac{d C(t \cdot F A R, t \cdot F I N)}{d t}\right|_{t=1}=\frac{\partial C(F A R, F I N)}{\partial F A R} \cdot F A R+\frac{\partial C(F A R, F I N)}{\partial F I N} \cdot F I N
$$

,we can express multistage scale economies as

$$
\begin{aligned}
& \operatorname{MSE}(F A R, F I N)= \\
& \qquad \frac{C(F A R, F I N)}{C(F A R, F I N)-\beta_{0}-\beta_{1} D F A R-\beta_{2} D F I N+\beta_{5} F A R^{2}+\beta_{6} F^{2} N^{2}+\beta_{7} F A R x F I N}
\end{aligned}
$$

for $F A R>0$ and / or FIN $>0$.

\section{Estimation}

The ARMS survey uses a "multi-phase, multi-frame, stratified, probability-weighted" sampling method (U. S. Department of Agriculture, Economic Research Service 2009). It is conducted in three phases, with the Phase III sample providing production information on a specific agricultural/livestock output. The Phase III sample for hog production, drawn from the population consisting of operations with 25 head or more, is conducted periodically. Our analysis uses data from the 2004 survey covering nineteen states. It was drawn from two lists (frames) under stratified sampling without replacement. One list contains known farm operations gathered from various sources while the other consists of randomly selected agricultural land segments. The stratified sampling leads to sample selection probabilities that differ across strata. Weighted least squares estimation of eq. (8), a procedure that weights each observation by a "survey weight," produces consistent estimates of the $\beta$ coefficients that are reflective of the population of hog producers in the U.S.

More precisely, with production costs for a given farm taking the form of the scalar eq. (8), denote the $n x 1$ vector equation giving production costs for the $n$ farms in the sample by $Y=X \beta+\mathrm{E}$, where $Y$ is the $n x 1$ vector of costs (C), $X$ is the $n x k$ matrix of independent variables in eq. (8) (a constant, DFAR, DFIN, FAR, etc.), $\beta$ is the $k x 1$ vector of the $\beta_{i}{ }^{\prime}$, and $\mathrm{E}$ is the $n x 1$ vector of the farm-specific error terms $(\varepsilon)$. The "census coefficient," denoted $\beta_{\text {Pop }}$, is a finite population quantity defined as the $k x 1$ vector of coefficients that would provide the best fit of the model, by the least-squares criterion, for the population of N U.S. hog farms:

$$
\beta_{\text {Pop }}=\underset{\beta}{\arg \min }\left(Y_{\text {Pop }}-X_{\text {Pop }} \beta\right)^{\prime}\left(Y_{\text {Pop }}-X_{\text {Pop }} \beta\right),
$$

where $Y_{\text {Pop }}$ and $X_{\text {Pop }}$ are the $N x 1$ and $N x k$ arrays of data for the population. DuMouchel and Duncan (1983) and Wooldridge (1999) show that a consistent estimator of the census coefficient, $\beta_{\text {Pop }}$, is provided by the weighted least-squares estimator:

$$
\hat{\beta}=\left(X^{\prime} W X\right)^{-1} X^{\prime} W Y,
$$

where $W$ is the $n x n$ diagonal matrix with survey weights as diagonal elements. The survey weights are provided in the ARMS data set and "are based on sampling weights (the inverses of the sample selection probabilities) and are adjusted for nonresponse and calibrated for known population quantities either through modeling or poststratification" (National Research Council 2007). Kott (2001) provides details of the calculation of the sampling weights. ${ }^{18}$ 
Estimation of the variances of these coefficient estimators must take account of the complex multi-phase sampling design used in the ARMS survey. One class of variance estimators applicable in this context is that of replication estimators that are based on variation in estimates across subsamples of the survey (Carrington, Eltinge, and McCue 2000). We use the delete-a-group jackknife variance estimator suggested by Kott (2001) and Dubman (2001). The delete-a-group jackknife procedure estimates the covariance matrix of $\hat{\beta}$, the weighted least squares estimator of $\beta_{\text {Pop }}$, as

$$
\hat{V}=\frac{14}{15} \sum_{r=1}^{15}\left(\hat{\beta}_{(r)}-\hat{\beta}\right)\left(\hat{\beta}_{(r)}-\hat{\beta}\right)^{\prime},
$$

where $\hat{V}$ denotes the estimated covariance matrix. The delete-a-group jackknife uses the survey weights reported in the ARMS dataset to calculate the full-sample weighted least squares estimate, $\hat{\beta}$, as described above. Fifteen additional sets of replicate weights are provided in the dataset. Each of these is constructed by zeroing out the weights attaching to approximately one fifteenth of the observations, and rescaling the remaining weights. Estimation using any one set of replicate weights essentially amounts to weighted least squares estimation of the model with one fifteenth of the observations deleted. Denoted $\hat{\beta}_{(r)}$, the $r^{\text {th }}$ weighted least squares replicate estimator is obtained using the $r^{\text {th }}$ set of replicate weights.

\section{Results}

The weighted least squares coefficient estimates are given in Table 1, along with delete-a-group jackknife standard errors and the corresponding $t$-values and $p$-values, computed following the NASS recommendation (Kott 2008) that the statistic $\left(\hat{\beta}_{i}-\beta_{i}\right) / \sqrt{\hat{v}_{i}}$ be treated as following a Student $t$ distribution with 14 degrees of freedom, where $\hat{v}_{i}$ is the $i^{\text {th }}$ diagonal entry of the estimated covariance matrix, $\hat{V}$. The estimated cost function fits the data fairly well as it accounts for over $92 \%$ of the total sum of squares $\left(R^{2}=0.9228\right)$. Only four of the twelve individual parameter estimates are significant at the $5 \%$ level or better but, as we shall see, estimates of the particular non-linear functions of parameters associated with the $S E S_{i}, V S E$, and MSE indices turn out to be statistically significant in many cases. ${ }^{19}$ eq. (8) has the cost function intercept depending on the type of operation: $\beta_{0}+\beta_{1}$ for completely specialized farrow-to-feeder operations, $\beta_{0}+\beta_{2}$ for completely specialized feeder-to-finish operations, and $\beta_{0}+\beta_{1}+\beta_{2}$ for fully or partially integrated operations. Thus $\beta_{0}$ can be thought of as the fixed cost "savings" that result from combining completely-specialized operations at the first and second stages into an integrated operation incorporating both stages. But with a negative and significant estimate of $\beta_{0}$, the implication is that there are net additional fixed costs incurred by the integrated farm. One example of how this might arise is additional fixed cost associated with a more complex management structure that more than offsets any savings due to elimination of the duplication of common indivisible equipment.

Table 1: Parameter estimates.

\begin{tabular}{|c|c|c|c|c|}
\hline Variable (Parameter) & $\begin{array}{l}\text { Coefficient } \\
\text { Estimate }\end{array}$ & $\begin{array}{l}\text { Standard } \\
\text { Error }\end{array}$ & t-value & p-value \\
\hline Intercept $\left(\beta_{0}\right)$ & $-37,440$ & $15,587.87$ & -2.40187 & 0.0308 \\
\hline $\operatorname{DFAR}\left(\beta_{1}\right)$ & 39,915 & $14,381.51$ & 2.775439 & 0.0149 \\
\hline $\operatorname{DFIN}\left(\beta_{2}\right)$ & 54,067 & $12,185.1$ & 4.437141 & 0.0006 \\
\hline FAR $\left(\beta_{3}\right)$ & 70.52230 & 129.3371 & 0.54526 & 0.5942 \\
\hline $\operatorname{FIN}\left(\beta_{4}\right)$ & 9.88467 & 9.185292 & 1.076141 & 0.3001 \\
\hline$F A R^{2}\left(\beta_{5}\right)$ & -0.00131 & $2.24 \mathrm{E}-03$ & -0.58608 & 0.5671 \\
\hline $\operatorname{FIN}^{2}\left(\beta_{6}\right)$ & -0.00002712 & $3.03018 \mathrm{E}-05$ & -0.89499589 & 0.3860 \\
\hline$F A R \times F I N\left(\beta_{7}\right)$ & 0.00033992 & 0.000412 & 0.824815 & 0.4233 \\
\hline PFEED $\times$ FAR $\left(\beta_{8}\right)$ & 0.93061 & 0.918945 & 1.012694 & 0.3284 \\
\hline PFEED $x$ FIN $\left(\beta_{9}\right)$ & 0.67872 & 0.235466 & 2.882455 & 0.0121 \\
\hline WAGE $\times \operatorname{FAR}\left(\beta_{10}\right)$ & 1.16919 & 6.18422 & 0.18906 & 0.8528 \\
\hline WAGE $\times \operatorname{FIN}\left(\beta_{11}\right)$ & 0.58725 & 0.48738 & 1.204912 & 0.2482 \\
\hline
\end{tabular}

The remaining parameter estimates, although insignificant in almost every case, have algebraic signs that are sensible. The coefficients on the linear output terms (FAR and $F I N)$ are positive while those on the squared outputs $\left(F A R^{2}\right.$ and $\left.F I N^{2}\right)$ are negative, suggesting that costs tend to increase at a decreasing rate in the output of each stage. The positive estimate of the coefficient of the cross-product term (FAR $x$ FIN), along with the 
negative estimate of $\beta_{0}$ will, in view of eq. (9), have implications about vertical scope economies to which we will turn presently. The coefficients of the terms in which an output measure is interacted with an input price are all positive suggesting, as one would expect, that costs increase with factor prices at a rate that increases with output.

The various measures of economies of scale and scope (eqs. 9 and 11 through 13) were estimated for output levels ranging up to 30,000 cwt. for the farrow-to-feeder stage and 120,000 cwt. for the feeder-to-finish stage, and for the sample average values of PFEED and WAGE (\$12 per hundred-weight of feed and $\$ 10$ per labor hour). Point estimates are presented in Table 2, Table 3, Table 4, and Table 5 for, respectively, stage-specific economies of scale for each stage, multistage economies of scale, and vertical scope economies. The farrow-tofeeder and feeder-to-finish output ranges for which the measures are reported in the tables correspond, roughly, to the ranges of each stage-specific output found in the data. The tables have diagonal cells exhibiting secondstage-to-first-stage output ratios of 4-to-1, corresponding roughly to fully integrated operations. ${ }^{20}$ To assess the statistical significance of the point estimates, standard errors were approximated using the delta method and a Student $t$ distribution with 14 degrees of freedom was assumed for statistics of the form $\left(\hat{\mathrm{B}}-\mathrm{B}_{0}\right) / \sqrt{\hat{v}_{\mathrm{B}}}$, where $\hat{\mathrm{B}}$ and $\mathrm{B}_{0}$ are the estimate and the null-hypothesized value, respectively, of a scale or scope economy measure $\left(S E S_{i}, M S E\right.$, or $\left.V S E\right)$ and $\hat{v}_{\mathrm{B}}$ is the delta-method-estimated variance of $\hat{\mathrm{B}}$. In the tables, the letter superscripts indicate significance levels of tests of null hypotheses that the index is equal to one versus the one-sided alternative that it is greater than one in the cases of $S E S_{1}, S E S_{2}$ and $M S E$. For the case of VSE, the reported significance levels are of tests of a null hypothesized zero value versus the one-sided alternative of a negative value. In the cases of stage-specific scale economies at the feeder-to-finish stage, multistage scale economies, and vertical scope economies, several of the point estimates are significantly different from the corresponding null-hypothesized value. Estimates associated with operations with outputs approaching the upper limits of the data range generally tend to be insignificant, however.

Table 2: Farrow-to-feeder stage-specific economies of scale $\left(\mathrm{SES}_{1}\right)$.

\begin{tabular}{lllllllllllll}
\hline & \multicolumn{2}{l}{ Farrow-to-feeder output (cwt.) } & & & & & & & \\
$\begin{array}{l}\text { Feeder-to-finish } \\
\text { output (cwt.) }\end{array}$ & $\mathbf{5 0 0}$ & $\mathbf{1 0 0 0}$ & $\mathbf{1 5 0 0}$ & $\mathbf{2 0 0 0}$ & $\mathbf{2 5 0 0}$ & $\mathbf{3 5 0 0}$ & $\mathbf{5 0 0 0}$ & $\mathbf{7 5 0 0}$ & $\mathbf{1 0 , 0 0 0}$ & $\mathbf{1 5 , 0 0 0}$ & $\mathbf{2 0 , 0 0 0}$ & $\mathbf{3 0 , 0 0 0}$ \\
\hline 0 & & & & & & & & & & & & \\
\hline 2000 & 1.061 & 1.042 & 1.040 & 1.044 & 1.049 & 1.063 & 1.088 & 1.138 & 1.199 & 1.366 & 1.642 & 3.664 \\
4000 & 1.868 & 1.451 & 1.317 & 1.254 & 1.220 & 1.188 & 1.180 & 1.204 & 1.252 & 1.407 & 1.677 & 3.628 \\
6000 & 1.861 & 1.448 & 1.315 & 1.252 & 1.218 & 1.187 & 1.178 & 1.202 & 1.249 & 1.402 & 1.666 & 3.517 \\
8000 & 1.855 & 1.444 & 1.312 & 1.250 & 1.217 & 1.185 & 1.177 & 1.200 & 1.247 & 1.398 & 1.655 & 3.415 \\
10,000 & 1.849 & 1.441 & 1.310 & 1.248 & 1.215 & 1.184 & 1.175 & 1.198 & 1.245 & 1.393 & 1.645 & 3.322 \\
14,000 & 1.843 & 1.438 & 1.308 & 1.247 & 1.213 & 1.183 & 1.174 & 1.196 & 1.242 & 1.388 & 1.635 & 3.235 \\
20,000 & 1.831 & 1.432 & 1.303 & 1.243 & 1.210 & 1.180 & 1.171 & 1.193 & 1.238 & 1.379 & 1.616 & 3.079 \\
30,000 & 1.814 & 1.423 & 1.297 & 1.238 & 1.206 & 1.176 & 1.167 & 1.188 & 1.231 & 1.366 & 1.590 & 2.883 \\
40,000 & 1.787 & 1.408 & 1.287 & $1.230^{\mathrm{c}}$ & $1.198^{\mathrm{c}}$ & 1.169 & 1.161 & 1.180 & 1.221 & 1.347 & 1.551 & 2.627 \\
60,000 & 1.762 & 1.395 & 1.277 & $1.222^{\mathrm{c}}$ & $1.192^{\mathrm{c}}$ & $1.163^{\mathrm{c}}$ & 1.155 & 1.173 & 1.212 & 1.330 & 1.517 & 2.432 \\
80,000 & 1.716 & 1.371 & $1.260^{\mathrm{c}}$ & $1.208^{\mathrm{c}}$ & $1.179^{\mathrm{c}}$ & $1.153^{\mathrm{c}}$ & 1.144 & 1.161 & 1.195 & 1.300 & 1.459 & 2.155 \\
120,000 & 1.675 & 1.349 & $1.245^{\mathrm{c}}$ & $1.196^{\mathrm{c}}$ & $1.169^{\mathrm{c}}$ & $1.144^{\mathrm{c}}$ & 1.135 & 1.150 & 1.181 & 1.275 & 1.414 & 1.968 \\
\hline
\end{tabular}

Superscripts: Estimate is statistically significantly greater than 1 at the $1 \% \mathrm{a}, 5 \% \mathrm{~b}, 10 \%{ }^{\mathrm{c}}$ level.

Table 3: Feeder-to-finish stage-specific economies of scale $\left(\mathrm{SES}_{2}\right)$.

\begin{tabular}{|c|c|c|c|c|c|c|c|c|c|c|c|c|c|}
\hline \multirow[b]{2}{*}{$\begin{array}{l}\text { Feeder-to-finish } \\
\text { output (cwt.) }\end{array}$} & \multicolumn{13}{|c|}{ Farrow-to-feeder output (cwt.) } \\
\hline & 0 & 500 & 1000 & 1500 & 2000 & 2500 & 3500 & 5000 & 7500 & 10,000 & 15,000 & 20,000 & 30,000 \\
\hline 2000 & $1.352^{\mathrm{c}}$ & $2.130^{\mathrm{a}}$ & $2.122^{\mathrm{a}}$ & $2.115^{\mathrm{a}}$ & $2.107^{\mathrm{a}}$ & $2.099^{\mathrm{a}}$ & $2.084^{\mathrm{a}}$ & $2.063^{\mathrm{a}}$ & $2.028^{\mathrm{a}}$ & $1.996^{\mathrm{a}}$ & $1.938^{\mathrm{a}}$ & $1.885^{\mathrm{b}}$ & $1.797^{\mathrm{b}}$ \\
\hline 4000 & $1.180^{c}$ & $1.571^{\mathrm{a}}$ & $1.567^{\mathrm{a}}$ & $1.563^{\mathrm{a}}$ & $1.559^{\mathrm{a}}$ & $1.555^{\mathrm{a}}$ & $1.548^{\mathrm{a}}$ & $1.537^{\mathrm{a}}$ & $1.519^{\mathrm{a}}$ & $1.503^{\mathrm{a}}$ & $1.473^{\mathrm{a}}$ & $1.447^{\mathrm{b}}$ & $1.402^{\mathrm{b}}$ \\
\hline 6000 & $1.124^{c}$ & $1.386^{\mathrm{a}}$ & $1.384^{\mathrm{a}}$ & $1.381^{\mathrm{a}}$ & $1.378^{\mathrm{a}}$ & $1.376^{\mathrm{a}}$ & $1.370^{\mathrm{a}}$ & $1.363^{\mathrm{a}}$ & $1.351^{\mathrm{a}}$ & $1.340^{\mathrm{a}}$ & $1.320^{\mathrm{a}}$ & $1.302^{\mathrm{b}}$ & $1.272^{\mathrm{b}}$ \\
\hline 8000 & $1.098^{\mathrm{c}}$ & $1.295^{\mathrm{a}}$ & $1.293^{\mathrm{a}}$ & $1.291^{\mathrm{a}}$ & $1.289^{\mathrm{a}}$ & $1.287^{\mathrm{a}}$ & $1.283^{\mathrm{a}}$ & $1.277^{\mathrm{a}}$ & $1.268^{\mathrm{a}}$ & $1.260^{\mathrm{a}}$ & $1.244^{\mathrm{a}}$ & $1.230^{\mathrm{b}}$ & $1.207^{\mathrm{b}}$ \\
\hline 10,000 & $1.083^{b}$ & $1.241^{\mathrm{a}}$ & $1.240^{\mathrm{a}}$ & $1.238^{\mathrm{a}}$ & $1.236^{\mathrm{a}}$ & $1.235^{\mathrm{a}}$ & $1.231^{\mathrm{a}}$ & $1.227^{\mathrm{a}}$ & $1.219^{\mathrm{a}}$ & $1.212^{\mathrm{a}}$ & $1.200^{\mathrm{a}}$ & $1.188^{\mathrm{b}}$ & $1.169^{b}$ \\
\hline 14,000 & $1.068^{b}$ & $1.182^{\mathrm{a}}$ & $1.181^{\mathrm{a}}$ & $1.179^{\mathrm{a}}$ & $1.178^{\mathrm{a}}$ & $1.177^{\mathrm{a}}$ & $1.174^{\mathrm{a}}$ & $1.171^{\mathrm{a}}$ & $1.165^{\mathrm{a}}$ & $1.160^{\mathrm{a}}$ & $1.150^{\mathrm{a}}$ & $1.142^{\mathrm{b}}$ & $1.127^{\mathrm{b}}$ \\
\hline 20,000 & $1.060^{\mathrm{b}}$ & $1.141^{\mathrm{a}}$ & $1.140^{\mathrm{a}}$ & $1.139^{\mathrm{a}}$ & $1.138^{\mathrm{a}}$ & $1.137^{\mathrm{a}}$ & $1.135^{\mathrm{a}}$ & $1.132^{\mathrm{a}}$ & $1.128^{\mathrm{a}}$ & $1.124^{\mathrm{b}}$ & $1.116^{\mathrm{b}}$ & $1.110^{\mathrm{b}}$ & $1.098^{\mathrm{b}}$ \\
\hline 30,000 & 1.061 & $1.117^{\mathrm{b}}$ & $1.116^{\mathrm{b}}$ & $1.115^{\mathrm{b}}$ & $1.114^{\mathrm{b}}$ & $1.113^{\mathrm{b}}$ & $1.111^{\mathrm{b}}$ & $1.109^{b}$ & $1.105^{\mathrm{b}}$ & $1.102^{\mathrm{b}}$ & $1.096^{\mathrm{c}}$ & $1.090^{c}$ & $1.081^{\mathrm{c}}$ \\
\hline & 1.069 & $1.111^{\mathrm{c}}$ & $1.110^{c}$ & $1.110^{c}$ & $1.109^{c}$ & $1.108^{c}$ & $1.106^{\mathrm{c}}$ & $1.104^{c}$ & $1.100^{c}$ & $1.097^{c}$ & $1.091^{\mathrm{c}}$ & 1.085 & 1.076 \\
\hline 60,000 & 1.092 & 1.121 & 1.120 & 1.120 & 1.119 & 1.118 & 1.116 & 1.113 & 1.109 & 1.105 & 1.098 & 1.092 & 1.082 \\
\hline
\end{tabular}


80,000

$\begin{array}{llllllllll}1.122 & 1.144 & 1.143 & 1.142 & 1.141 & 1.139 & 1.137 & 1.134 & 1.129 & 1.124\end{array}$

1.115

1.108

1.096

120,000

$\begin{array}{lll}1.195 & 1.211 & 1.209\end{array}$

1.207

$1.205 \quad 1.203 \quad 1.199$

1.194

$1.186 \quad 1.178$

1.165

1.153

1.134

Superscripts: Estimate is statistically significantly greater than 1 at the $1 \%{ }^{\mathrm{a}}, 5 \%{ }^{\mathrm{b}}, 10 \%{ }^{\mathrm{c}}$ level.

Table 4: Multistage economies of scale (MSE).

\begin{tabular}{lllllllllllllll}
\hline & \multicolumn{1}{l}{ Farrow-to-feeder output (cwt.) } & & & & & & & \\
$\begin{array}{l}\text { Feeder-to-finish } \\
\text { output (cwt.) }\end{array}$ & $\mathbf{0}$ & $\mathbf{5 0 0}$ & $\mathbf{1 0 0 0}$ & $\mathbf{1 5 0 0}$ & $\mathbf{2 0 0 0}$ & $\mathbf{2 5 0 0}$ & $\mathbf{3 5 0 0}$ & $\mathbf{5 0 0 0}$ & $\mathbf{7 5 0 0}$ & $\mathbf{1 0 , 0 0 0}$ & $\mathbf{1 5 , 0 0 0}$ & $\mathbf{2 0 , 0 0 0}$ & $\mathbf{3 0 , 0 0 0}$ \\
\hline 0 & 1.061 & 1.042 & 1.040 & 1.044 & 1.049 & 1.063 & 1.088 & 1.138 & 1.199 & 1.366 & 1.642 & 3.664 \\
2000 & $1.352^{\mathrm{c}}$ & $1.601^{\mathrm{a}}$ & $1.410^{\mathrm{b}}$ & $1.319^{\mathrm{b}}$ & $1.267^{\mathrm{c}}$ & $1.236^{\mathrm{c}}$ & $1.203^{\mathrm{c}}$ & 1.189 & 1.205 & 1.247 & 1.388 & 1.634 & 3.285 \\
4000 & $1.180^{\mathrm{c}}$ & $1.398^{\mathrm{a}}$ & $1.302^{\mathrm{a}}$ & $1.248^{\mathrm{b}}$ & $1.215^{\mathrm{b}}$ & $1.194^{\mathrm{b}}$ & $1.171^{\mathrm{c}}$ & 1.163 & 1.180 & 1.220 & 1.350 & 1.572 & 2.928 \\
6000 & $1.124^{\mathrm{c}}$ & $1.300^{\mathrm{a}}$ & $1.240^{\mathrm{a}}$ & $1.204^{\mathrm{a}}$ & $1.180^{\mathrm{a}}$ & $1.164^{\mathrm{b}}$ & $1.147^{\mathrm{b}}$ & 1.142 & 1.160 & 1.197 & 1.317 & 1.519 & 2.662 \\
8000 & $1.098^{\mathrm{c}}$ & $1.242^{\mathrm{a}}$ & $1.200^{\mathrm{a}}$ & $1.173^{\mathrm{a}}$ & $1.155^{\mathrm{a}}$ & $1.143^{\mathrm{a}}$ & $1.129^{\mathrm{b}}$ & $1.126^{\mathrm{c}}$ & 1.143 & 1.177 & 1.289 & 1.473 & 2.455 \\
10,000 & $1.083^{\mathrm{b}}$ & $1.205^{\mathrm{a}}$ & $1.173^{\mathrm{a}}$ & $1.151^{\mathrm{a}}$ & $1.136^{\mathrm{a}}$ & $1.126^{\mathrm{a}}$ & $1.115^{\mathrm{a}}$ & $1.112^{\mathrm{c}}$ & 1.128 & 1.161 & 1.264 & 1.433 & 2.290 \\
14,000 & $1.068^{\mathrm{b}}$ & $1.160^{\mathrm{a}}$ & $1.138^{\mathrm{a}}$ & $1.122^{\mathrm{a}}$ & $1.111^{\mathrm{a}}$ & $1.103^{\mathrm{a}}$ & $1.094^{\mathrm{a}}$ & $1.092^{\mathrm{c}}$ & 1.105 & 1.133 & 1.223 & 1.368 & 2.043 \\
20,000 & $1.060^{\mathrm{b}}$ & $1.126^{\mathrm{a}}$ & $1.110^{\mathrm{a}}$ & $1.098^{\mathrm{a}}$ & $1.089^{\mathrm{a}}$ & $1.083^{\mathrm{a}}$ & $1.075^{\mathrm{b}}$ & $1.071^{\mathrm{c}}$ & 1.081 & 1.103 & 1.177 & 1.294 & 1.797 \\
30,000 & 1.061 & $1.105^{\mathrm{b}}$ & $1.092^{\mathrm{b}}$ & $1.082^{\mathrm{c}}$ & $1.074^{\mathrm{c}}$ & $1.068^{\mathrm{c}}$ & 1.059 & 1.054 & 1.057 & 1.071 & 1.125 & 1.212 & 1.554 \\
40,000 & 1.069 & $1.101^{\mathrm{c}}$ & $1.089^{\mathrm{c}}$ & 1.079 & 1.071 & 1.064 & 1.054 & 1.046 & 1.044 & 1.052 & 1.091 & 1.158 & 1.409 \\
60,000 & 1.092 & 1.111 & 1.099 & 1.088 & 1.079 & 1.071 & 1.059 & 1.046 & 1.036 & 1.035 & 1.054 & 1.094 & 1.248 \\
80,000 & 1.122 & 1.132 & 1.119 & 1.108 & 1.098 & 1.089 & 1.074 & 1.057 & 1.040 & 1.032 & 1.037 & 1.061 & 1.163 \\
120,000 & 1.195 & 1.196 & 1.180 & 1.166 & 1.153 & 1.141 & 1.120 & 1.095 & 1.066 & 1.048 & 1.032 & 1.034 & 1.081 \\
\hline
\end{tabular}

Superscripts: Estimate is statistically significantly greater than 1 at the $1 \%^{\mathrm{a}}, 5 \%{ }^{\mathrm{b}}, 10 \%^{\mathrm{c}}$ level.

Table 5: Vertical economies of scope (VSE).

\begin{tabular}{|c|c|c|c|c|c|c|c|c|c|c|c|c|}
\hline \multirow[b]{2}{*}{$\begin{array}{l}\text { Feeder-to-finish } \\
\text { Output (cwt.) }\end{array}$} & \multicolumn{12}{|c|}{ Farrow-to-feeder output (cwt.) } \\
\hline & 500 & 1000 & 1500 & 2000 & 2500 & 3500 & 5000 & 7500 & 10,000 & 15,000 & 20,000 & 30,000 \\
\hline 2000 & $-0.250^{b}$ & $-0.194^{b}$ & $-0.159^{b}$ & $-0.135^{c}$ & $-0.118^{c}$ & $-0.095^{c}$ & $-0.075^{c}$ & -0.058 & -0.048 & -0.039 & -0.035 & -0.033 \\
\hline 4000 & $-0.192^{b}$ & $-0.158^{b}$ & $-0.136^{\mathrm{b}}$ & $-0.120^{\mathrm{b}}$ & $-0.107^{\mathrm{b}}$ & $-0.090^{c}$ & $-0.075^{\mathrm{c}}$ & $-0.060^{c}$ & -0.053 & -0.045 & -0.042 & -0.043 \\
\hline 6000 & $-0.156^{\mathrm{a}}$ & $-0.135^{\mathrm{b}}$ & $-0.119^{b}$ & $-0.108^{b}$ & $-0.099^{b}$ & $-0.086^{\mathrm{b}}$ & $-0.074^{c}$ & $-0.063^{c}$ & -0.057 & -0.051 & -0.049 & -0.052 \\
\hline 8000 & $-0.132^{\mathrm{a}}$ & $-0.118^{\mathrm{a}}$ & $-0.107^{\mathrm{a}}$ & $-0.099^{b}$ & $-0.093^{b}$ & $-0.083^{b}$ & $-0.074^{c}$ & $-0.065^{c}$ & -0.060 & -0.056 & -0.056 & -0.061 \\
\hline 10,000 & $-0.115^{\mathrm{a}}$ & $-0.105^{\mathrm{a}}$ & $-0.098^{\mathrm{a}}$ & $-0.092^{\mathrm{a}}$ & $-0.087^{\mathrm{b}}$ & $-0.080^{b}$ & $-0.073^{c}$ & $-0.067^{c}$ & -0.063 & -0.061 & -0.062 & -0.069 \\
\hline 14,000 & $-0.092^{\mathrm{a}}$ & $-0.087^{a}$ & $-0.084^{\mathrm{a}}$ & $-0.081^{\mathrm{a}}$ & $-0.079^{a}$ & $-0.076^{b}$ & $-0.073^{c}$ & -0.070 & -0.069 & -0.070 & -0.073 & -0.084 \\
\hline 20,000 & $-0.071^{\mathrm{a}}$ & $-0.071^{\mathrm{a}}$ & $-0.071^{\mathrm{a}}$ & $-0.071^{\mathrm{a}}$ & $-0.071^{\mathrm{a}}$ & $-0.071^{b}$ & $-0.072^{c}$ & -0.074 & -0.076 & -0.081 & -0.087 & -0.103 \\
\hline 30,000 & $-0.053^{a}$ & $-0.056^{\mathrm{a}}$ & $-0.058^{\mathrm{a}}$ & $-0.061^{\mathrm{a}}$ & $-0.063^{b}$ & $-0.067^{b}$ & $-0.072^{c}$ & -0.078 & -0.084 & -0.095 & -0.105 & -0.128 \\
\hline 40,000 & $-0.043^{\mathrm{a}}$ & $-0.047^{\mathrm{a}}$ & $-0.051^{\mathrm{a}}$ & $-0.055^{\mathrm{b}}$ & $-0.058^{b}$ & $-0.064^{c}$ & $-0.072^{c}$ & -0.082 & -0.091 & -0.106 & -0.120 & -0.148 \\
\hline 60,000 & $-0.033^{\mathrm{a}}$ & $-0.038^{\mathrm{a}}$ & $-0.044^{\mathrm{b}}$ & $-0.048^{\mathrm{b}}$ & $-0.053^{c}$ & $-0.061^{\mathrm{c}}$ & -0.072 & -0.088 & -0.101 & -0.122 & -0.142 & -0.179 \\
\hline 80,000 & $-0.028^{\mathrm{a}}$ & $-0.034^{\mathrm{b}}$ & $-0.040^{\mathrm{b}}$ & $-0.045^{c}$ & $-0.050^{c}$ & -0.060 & -0.073 & -0.092 & -0.108 & -0.135 & -0.158 & -0.202 \\
\hline 120,000 & $-0.022^{b}$ & $-0.029^{b}$ & $-0.036^{c}$ & $-0.043^{c}$ & -0.049 & -0.060 & -0.076 & -0.099 & -0.119 & -0.153 & -0.182 & -0.234 \\
\hline
\end{tabular}

Superscripts: Estimate is statistically significantly less than 0 at the $1 \%^{\mathrm{a}}, 5 \%{ }^{\mathrm{b}}, 10 \%{ }^{\mathrm{c}}$ level.

Our results differ markedly from those of Azzam and Skinner (2007) in a number of respects. For both stages of production, Azzam and Skinner found regions of stage-specific economies of scale, and regions of stagespecific diseconomies of scale. ${ }^{21}$ Our point estimates of $S E S_{1}$ and $S E S_{2}$ are uniformly greater than one, indicating stage-specific economies of scale, throughout. In the case of $S E S_{1}$, point estimates are generally insignificantly greater than one. For the feeder-to-finish stage, however, estimates of $S E S_{2}$ are statistically greater than one throughout the output range of the Azzam and Skinner data and, indeed, throughout most of the output space spanned by our data. ${ }^{22}$ In the case of multistage economies of scale, a comparison of our results with those of Azzam and Skinner reveals a similar pattern. Azzam and Skinner find evidence of multistage economies of scale in some regions and evidence of multistage diseconomies of scale in other regions. Our point estimates of MSE are uniformly greater than one and statistically significantly greater than one in many cases. Certainly for the region of output space up to $3500 \mathrm{cwt}$. at the farrow-to-feeder stage and up to 20,000 cwt. at the feeder-tofinish stage there is strong evidence that equal proportional increases in output at both stages would result in a less-than-proportional increase in cost. Beyond these output limits, statistical significance of MSE estimates is 
generally lacking, but at least it can be said that we find no evidence that diseconomies of scale set in anywhere in the output range of our sample.

The results for the vertical scope economies measure provide our most economically significant departure from the findings of Azzam and Skinner. Azzam and Skinner's estimates of VSE were uniformly positive throughout the output range of their data, suggesting that vertical integration of the two production stages in a single establishment yields cost savings. Again, the significance of this result is its implication that the ultimate extinction of the traditional, small-scale, farrow-to-finish operations need not be the inevitable outcome of current industry trends: Traditional hog farms might be able to remain competitive with large scale specialized operations by taking advantage of vertical economies of scope. Our results, in contrast, provide no evidence of vertical economies of scope. In fact, our point estimates of VSE are uniformly negative, and often statistically significantly so, suggesting vertical diseconomies of scope, throughout the range of our data.

\section{Concluding Remarks}

Hog production in the U.S. has traditionally occurred primarily in relatively small scale operations that encompassed all phases of the production process from breeding and gestation through finishing. But the current trend in the structure of the industry is toward operations that are not only larger, but more specialized as well, carrying out only some of the vertically-related phases of production in a given facility. It is natural to assume that cost efficiency considerations are among the drivers of these changes in industry structure but, in order to investigate the cost incentives behind the current changes, one must adopt an approach that enables measurement of both scale and scope economies. In a 2007 paper, Azzam and Skinner took precisely this approach in a study that estimated a multistage cost function for hog production based on a view of the process involving two potentially separable stages: farrow-to-feeder and feeder-to-finish. Their results provided some evidence of economies of scale at both stages of production and, to this extent, supported the plausible inference that hog farms are getting bigger simply because bigger means more efficient. They also found evidence, however, of economies of scope in hog production; that is, evidence that combining both stages of production into an integrated farrow-to-finish farm yields cost savings. This finding suggests that relatively small scale operations that take advantage of these economies of scope by combining both stages of production in a single facility might still be able to compete with larger, specialized operations.

These conclusions were derived, however, from analysis of data from a nonrandom sample of hog producers prior to 1996. In this article, we have used the 2004 ARMS data on hog farm costs to re-estimate a multistage cost function for hog production. Based on these more recent and more representative data, and utilizing estimation techniques appropriate given ARMS' complex sampling methodology, we reached quite different conclusions about the cost structure of the industry. Our findings provide strong evidence of not only economies of scale, particularly in the feeder-to-finish stage, but also vertical diseconomies of scope, suggesting that the integration of the two vertically-related stages is actually inefficient. In view of these results, one needs look no further than cost efficiency explanations for the ongoing changes in the size distribution and vertical organization of the industry.

\section{Funding}

National Research Initiative Competitive Grants Program (Markets and Trade area), CSREES/USDA., (Grant / Award Number: '2007-04495').

\section{Appendix: The Measurement of Stage-Specific Output}

The stage one and stage two output measures used in the multistage cost function are hundred weight gain in the farrow-to-feeder (FAR) and the feeder-to-finish stages (FIN) during calendar year 2004, the period to which the ARMS Phase III survey applied. Since output at the farrow-to-feeder stage includes, for some farms, feeder pigs that are then transferred internally, and since the number of these internal transfers must be inferred from stocks and flows at the second stage, we start by considering output at the feeder-to-finish stage. 


\section{Output Measure: Stage 2}

FIN, the hundred weight gain at the feeder-to-finish stage, was calculated as the weight of market hogs sold/removed, plus the change in the weight of the inventory of hogs in the feeder-to-finish stage, minus the weight of feeder pigs supplied as inputs to the stage. Firms can acquire feeder pigs for input into their second stage production by transferring them internally or purchasing/placing them. No feeder pigs are produced under completely specialized feeder-to-finish operations so all must be acquired through purchase/placement, and the number of feeder pigs purchased or placed is reported in the survey. For all other firms, however, the number of head of feeder pigs entering the feeder-to-finish stage (HDFPIn) is not directly reported in the survey but can be determined by adding the outflow of market hogs exiting the stage due to sale (HDMHSold) or death loss (FeedFinDL) to the net change in market hog inventory (HDFeedFin $\triangle I n v)$ :

$$
\text { HDFPIn }=\mid \begin{aligned}
& \text { HDFPPurch, for completely specialized feeder }- \text { to }- \text { finish } \\
& \text { HDMHSold }+ \text { FeedFinDL }+ \text { HDFeedFin } \Delta \text { Inv, otherwise }
\end{aligned}
$$

where HDFPPurch is the number of head of feeder pigs purchased/placed. ${ }^{23}$ Given the number of feeder pigs used as a second stage input, the total weight is calculated by multiplying by the average weight of feeder pigs in hundred-weight $(A v g C w t F P)$. For farms that purchased/placed or sold/removed feeder pigs, AvgCwtFP was set equal to the reported average weight of pigs involved in these transactions and was thus a measure specific to the farm. Fully-integrated farrow-to-feeder operations do not have external transactions in feeder pigs so, for these farms, $A v g C w t F P$ was set equal to the sample average weight of feeder pigs purchase/placed or sold/removed by all farms, approximately 47 pounds. The hundred weight of feeder pig input to the second stage is then calculated as

\section{$C w t F P I n=A v g C w t F P x$ HDFPIn.}

Beginning-of-year and end-of-year head count inventories were reported separately in the survey for four size categories: 0-59 pounds, $60-119$ pounds, $120-179$ pounds, and 180 pounds and over. Hogs in the last three categories, and some of the hogs in the first category, are attributed to the feeder-to-finish stage. As the average weight of feeder pigs observed is less than 60 pounds, the inventory of hogs in the $0-59$ pound category must be allocated between the farrow-to-feeder and feeder-to-finish stages. The allocation was based on the assumption that the pigs in this size category were uniformly distributed over weights of 0 to 60 pounds. This also implies that the average weight of the pigs in excess of 47 pounds is the average of 47 and 60 , the category's upper bound weight. Thus the hundred weight change in feeder-to-finish inventory of pigs weighing 47 to 60 pounds $\left(C w t F e e d F i n \Delta I n v_{47-59}\right)$ is calculated as

$$
\text { CwtFeedFin } \Delta \operatorname{Inv}_{47-59}=\frac{0.6+0.47}{2} \cdot \frac{60-47}{60} \cdot\left(\text { HDEndInv }{ }_{0-59}-H D B e g I n v_{0-59}\right),
$$

where $H D B e g I n v_{0-59}$ and $H D E n d I n v_{0-59}$ are beginning and ending inventories of pigs under 60 pounds.

The representative weights of the other three categories, 100 pounds, 150 pounds, and 200 pounds, are the category weights implicit in the ERS/NASS calculations of the hundred-weight inventory variables from the reported head-count inventories. Thus, the hundred weight inventory changes in the remaining categories are constructed as:

$$
\begin{aligned}
& \text { CwtFeedFin } \triangle I n v_{60-119}=1.0 \cdot\left(H D E n d I n v_{60-119}-H D B e g I n v_{60-119}\right) \\
& \text { CwtFeedFin } \triangle \operatorname{Inv}_{120-179}=1.5 \cdot\left(\text { HDEndInv }_{120-179}-H_{D B e g I n v}{ }_{120-179}\right) \\
& \text { CwtFeedFin } \Delta I n v_{180+}=2.0 \cdot\left(H D E n d I n v_{180+}-H D B e g I n v_{180+}\right) \text {, }
\end{aligned}
$$

where the new notation is defined in the obvious way. Summing these, we have the hundred weight change in feeder-to-finish inventory

$$
\begin{aligned}
\text { CwtFeedFin } \Delta I n v= & \text { CwtFeedFin } \Delta I n v_{47-59}+\text { CwtFeedFin } \Delta I n v_{60-119}+ \\
& \text { CwtFeedFin } \Delta I n v_{120-179}+\text { CwtFeedFin } \Delta I n v_{180+}
\end{aligned}
$$


Since both head of market hogs sold/removed (HDMHSold) and the average weight of market hogs sold/removed $(\operatorname{Avg} W t M H)$ were reported, the hundred weight of market hogs sold can be calculated as

CwtMHOut $=$ AvgWtMH $x$ HDMHSold $/ 100$.

Finally, the stage two output is

$$
\text { FIN }=C w t M H O u t+C w t F e e d F i n \Delta I n v-C w t F P I n .
$$

\section{Output Measure: Stage 1}

At the first stage, no output is produced by completely specialized feeder-to-finish operations. Since there is no intermediate input required for the farrow-to-feeder stage, the process of calculating hundred-weight gain is divided into only two parts: feeder pigs exiting the stage and change in inventory.

As previously mentioned, the survey reports head counts of pigs under 60 pounds in beginning-of-year $\left(H D B e g I n v_{0-59}\right)$ and end-of-year inventory $\left(H D E n d I n v_{0-59}\right)$. Just as before, we allocate these inventory totals between the farrow-to-feeder and feeder-to-finish stages based on the assumption of a uniform distribution of weights within the $0-60$ pound category. With 47 pounds taken to be the top weight of the farrow-to-feeder stage, we have the following beginning- and end-of-year inventory head counts:

$$
\text { HDFarFeedBegInv }=\frac{47}{60} \cdot \text { HDBegInv }{ }_{0-59}
$$

and

$$
\text { HDFarFeedEndInv }=\frac{47}{60} \cdot \text { HDEndInv } v_{0-59} .
$$

Assuming the average weight of feeder pigs in these beginning and ending inventories is half the average feeder pig weight, the hundred weight change in the pig inventory is

$$
\text { CwtFarFeed } \Delta I n v=\frac{0.47}{2}(\text { HDFarFeedEndInv }- \text { HDFarFeedBegInv }) .
$$

The outflow of feeder pigs from the first stage to the second (HDFPOut) occurs through either internal transfer or sale on the market. Thus, the number of feeder pigs exiting the farrow-to-feeder stage is

$$
\text { HDFPOut }=\text { HDFPSold }+(\text { HDFPIn }- \text { HDFPPurch }),
$$

where HDFPSold, the number of feeder pigs sold/removed, is reported in the survey. The hundred-weight of feeder pigs exiting the farrow-to-feeder stage is then

$$
\text { CwtFPOut }=\text { AvgCwtFP } x \text { HDFPOut. }
$$

From this, stage one output is given by

$$
F A R=C w t F P O u t+C w t F a r F e e d \Delta I n v .
$$




\title{
Death Loss Allocation
}

To determine the head count flows we require a measure of death loss at the feeder-to-finish stage. However, death losses were instead reported for pre-wean and post-wean periods - with weaning, of course, occurring during the farrow-to-feeder stage - so an allocation of the reported post-wean death losses (PstwDL) between the two stages was required for farms that operate at both stages. To achieve this, we calculated post-wean death loss ratios for completely specialized farrow-to-feeder and completely specialized feeder-to-finish operations as the number of weaned pigs that died before reaching market weight per feeder pig or per market hog sold/removed, respectively. These two producer types were selected as they operate exclusively on one stage or the other, and so reported death losses can be attributed entirely to a single stage of production. Sample averages of the post-wean death loss ratios were then generated for these two producer types. By dividing the average post-wean death loss ratio for feeder-to-finish operations by the sum of the average post-wean death loss ratios for both types of specialized operations, we obtained a rough estimate of the proportion of post-wean death losses that occur in the second stage of production (PstwPstfDLprop). This figure was then assumed to be applicable to all farms operating at both stages.

Completely specialized farrow-to-feeder farms have no second stage production so no death loss is allocated to the feeder-to-finish stage. Similarly, completely specialized feeder-to-finish farms operate exclusively on the second stage so all post-wean death loss is allocated to the feeder-to-finish stage. Since fully-integrated feeder-tofinish, partially-integrated backward, and partially-integrated forward firms operate on both stages, a portion of post-wean death loss is allocated to each stage. For these farms, farm-specific death loss at the feeder-tofinish stage (FeedFinDL) was calculated by multiplying the industry-wide proportion of post-wean death loss attributable to the second stage, PstwPstfDLprop, by the farm's reported number of post-wean deaths:

\author{
FeedFinDL $=$ PstwPstfDLprop $x$ PstwDL.
}

\section{Notes}

1 The first three phases of production are sometimes accomplished in two separate stages: a farrow-to-weanling stage incorporating the breeding/gestation and farrowing phases, in which pigs are farrowed and raised up to weaning, and a weanling-to-feeder stage performing the nursery phase of production, in which weanlings are raised to feeder pig weight of approximately 50 pounds.

2 Two other significant recent changes in the economics of hog production, although not the focus of this article, are a shift in the industry's geographic distribution and growth in the use of production contracts. Hog production was once largely concentrated in the Corn Belt states, but the years from 1992 to 2004 were a period of substantial growth of the industry in non-traditional locations such as North Carolina. Production contracts accounted for only $5 \%$ of U.S. hog production in 1992 but $67 \%$ by 2004 (Key and McBride 2007).

3 For example, Key and McBride's (2007) analysis of the 2004 ARMS data for feeder-to-finish operations yields estimates of scale elasticities in excess of one for farms in all size ranges. Scale elasticities exceeding one mean that equal-proportional simultaneous increases in all inputs produce a more than proportional increase in output, contributing to a tendency for larger scale feeder-to-finish operations to achieve lower average costs.

4 One theory, for example, is that small, traditional hog producers may have limited access to contracts. Operation under production or marketing contracts has the potential to benefit farmers through reduction in price and income risk and through the avoidance of transaction costs associated with spot market sales (MacDonald et al. 2004). Contract operation is much more common among large hog producers (Key and McBride 2007).

5 Mayen, Balagtas, and Alexander (2009) is a more recent study of vertical cost relationships in agriculture.

6 A simple example will illustrate this point. In a two-stage production process, assume that one unit of upstream product is needed to produce one unit of downstream product. Let the cost of producing one unit of upstream product in a disintegrated operation be one dollar: $C(1,0)=1$. Further, let $p$ be the expenditure required to obtain one unit of upstream product, the intermediate input, on the market. Let the cost of producing one unit of downstream product in a disintegrated operation be $C(0,1)=1+p$, prior to netting out the amount, $p$, spent on the intermediate input. Finally, assume that there are no economies of scope, so that the cost of producing one unit of the downstream product for the integrated firm that also produces the intermediate input and transfers it internally is $C(1,1)=2$. Due to the absence of economies of scope, the total cost of producing one unit of downstream product should be the same regardless of whether a single integrated firm is used or two firms, each operating exclusively on a single stage, are linked together. If the expenditure required to obtain one unit of the upstream product is not netted out of costs for the downstream firm, the total cost for the two linked firms would appear to be $C(1,0)+C(0,1)=2+p>2=C(1,1)$, thus giving the false impression of vertical economies of scope.

7 As Key and McBride (2007) note, by measuring output in this way, rather than in number of head marketed, account is taken of changes in inventory and differences across operations in average weights of feeder pigs and market hogs. This is also the approach to measurement of stage-specific output used in Azzam and Skinner (2007).

8 Sampled entities are "producers;" that is, sites at which hog production occurs; rather than owners. An individual hog owner may have growers producing under contract at multiple sites.

9 In the language of the survey, acquisitions of feeder pigs or weanlings (nursery pigs) under the terms of operating contracts were described as "placements." Likewise, contract shipments of weanlings, feeder pigs, or hogs were called "removals." The terms "purchases" and "sales" were reserved for arms-length market transactions.

10 One can imagine a third type of partially integrated operation: a farm that possesses both stages of production and, within the course of a single year, engages in both sales and purchases of feeder pigs. This kind of "partially integrated forward and backward" operation might 
arise, for example, if a producer intending to operate on a fully integrated basis finds that random fluctuations in death loss rates lead to feeder pig output that sometimes exceeds and sometimes falls short of the capacity of the farm's feeder-to-finish facility. Maintaining nearcapacity operation might then require both purchases and sales of feeder pigs at different times in a single year. Only one of the sampled producers displayed this kind of operation for the sample year and it was excluded from estimation.

11 The survey reported, for each farm, whether it was involved in each of four stages of production: breeding and gestating, farrowing, nursery, and growing/finishing. So, for example, a farm that reported sales of market hogs but did not claim involvement in the "growing/finishing" stage of production was considered to be inconsistent and was not used in estimation.

12 The breakdown of the final sample of 744 operations is as follows: fully integrated - 31\%, completely specialized farrow-to-feeder $8 \%$, completely specialized feeder-to-finish $-51 \%$, partially integrated backward - 3\%, partially integrated forward - $7 \%$.

13 Equation (8) gives costs for active operations with $F A R>0$ and/or $F I N>0$. With $F A R=F I N=0$, cost is zero.

14 The ARMS survey solicited information about the period of operation corresponding to calendar year 2004. Thus the cost and output variables are totals for this year.

15 The construction of these variables is detailed in the Appendix.

16 Our feed price variable, PFEED, in dollars per hundred-weight, was determined by dividing total feed cost ("COSTFEED" in the ARMS dataset) by the total hundred weight of feed fed ("CWTFEED"). Feed cost included the opportunity cost of homegrown feed as well as expenditure on purchased feeds. Opportunity costs of homegrown feed were based on market price data from secondary sources. Our price of labor, WAGE, in dollars per hour, is ARMS' unpaid wage rate ("UWAGE") variable which estimates the opportunity cost of operator-supplied labor using wage data from secondary sources.

17 The first term in the incremental cost function introduces a discontinuity at $F I N=0$ to account for the fact that cost is zero when no output is produced at either stage. Thus, when no second-stage output is produced, the incremental cost function for the farrow-to-feeder stage is

$$
C_{1}(F A R, 0)=\beta_{0}+\beta_{1}+\left(\beta_{3}+\beta_{8} P F E E D+\beta_{10} W A G E\right) \cdot F A R+\beta_{5} F A R^{2}
$$

This yields stage-specific scale economies equal to multistage economies along the relevant axis. For example: $S E S_{1}(F A R, 0)=$ $\operatorname{MSE}(F A R, 0)$ for all $F A R>0$.

18 In this setting, one could also imagine the finite population as having been drawn from a super-population model such as: $Y_{P o p} \sim$ $G_{N}\left(X_{P o p} \beta^{*}, \sigma^{2} 1 p t I\right)$, where $G_{N}$ is the Gaussian distribution, $\beta^{*}$ is the $k x 1$ vector of regression coefficients and $\sigma^{2}$ is the error variance characterizing the super-population. In this case, $\beta_{\text {Pop }}$ is the maximum likelihood estimator of $\beta^{*}$ and $\hat{\beta}$ is a consistent estimator of $\beta^{*}$. For the purposes of this study, we restrict attention to consistent estimation of $\beta_{P o p}$, using weighted least-squares, and ignore any consideration of a super-population model. Little (2004) provides a discussion of design-based vs. model-based inference.

19 This is perhaps unsurprising given that every one of the quantitative regressors is a function of one or both of the output measures, FAR and FIN. With a high degree of multicollinearity among independent variables, insignificance of individual parameter estimates combined with "joint" significance of the estimates of certain functions of parameters is a likely outcome.

20 The average weight of feeder pigs purchased/placed or sold/removed in the sample is 47.6 lbs. The average weight of market hogs sold/removed is 257.7 lbs., giving a ratio of weight gains at the two stages of 4.41 to 1 .

21 Their evidence consists of point estimates alone. No standard errors of scale or scope economy measures were reported in Azzam and Skinner.

22 The maximum farrow-to-feeder and feeder-to-finish output levels reflected in the Azzam and Skinner data were approximately 7500 cwt. and 18,000 cwt., respectively.

23 The calculation of death loss in the feeder-to-finish stage (FeedFinDL) is discussed in detail in a subsequent section.

\section{References}

Azzam, A., and C.S. Skinner. 2007. “Vertical Economies and the Structure of U.S. Hog Farms.” Canadian Journal of Agricultural Economics 55:349-364.

Bailey, E.E., and A.F. Friedlaender. 1982. "Market Structure and Multiproduct Industries." Journal of Economic Literature 20:1024-1048.

Baumol, W.J. 1977. “On the Proper Cost Tests for Natural Monopoly in a Multiproduct Industry.” American Economic Review 67 (5):809-822.

Carrington, W.J., J.L. Eltinge, and K. McCue. 2000. An Economist's Primer on Survey Samples. Discussion Paper CES 00-15, Center for Economic Studies, Bureau of the Census.

Dubman, R.W. 2001. Variance Estimation with USDA's Farm Costs and Returns Surveys and Agricultural Resource Management Study Surveys. ERS Staff Paper ACES 00-01. USDA-ERS.

DuMouchel, W.H., and G.J. Duncan. 1983. “Using Sample Survey Weights in Multiple Regression Analyses of Stratified Samples." Journal of the American Statistical Association 78 (383):535-543.

Kaserman, D.L., and J.W. Mayo. 1991. "The Measurement of Vertical Economies and the Efficient Structure of the Electric Utility Industry." Journal of Industrial Economics 39 (5):483-502.

Key, N., and W. McBride. 2007. The Changing Economics of U.S. Hog Production. Economic Research Report No. 52. USDA-ERS.

Kott, P.S. 2001. Using the Delete-a-Group Jackknife Variance Estimator in Nass Surveys. NASS Research Report 98-01 (revised 2001). Available at: http://www.nass.usda.gov/research/reports/RRC]7.pdf

Kott, P.S. 2008. Building a Better Delete-A-Croup Jackknife for a Calibration Estimator (Like that Based on Data from the ARMS III). Extension of paper presented at the Workshop on Calibration and Estimation in Surveys, Ottawa, Ontario, October/November 2007.

Kwoka, J.E. 2002. "Vertical Economies in Electric Power: Evidence on Integration and Its Alternatives." International Journal of Industrial Organization 20:653-671.

Little, R.J. 2004. "To Model or Not to Model? Competing Modes of Inference for Finite Population Sampling." Journal of the American Statistical Association 99:546-556.

MacDonald, J., J. Perry, M. Ahearn, D. Banker, W. Chambers, C. Dimitri, N. Key, K. Nelson, and L. Southard. 2004. Contracts, Markets, and Prices: Organizing the Production and Use of Agricultural Commodities. Agricultural Economics Report No. 837. USDA-ERS. 
Mayen, C.D., J.V. Balagtas, and C.E. Alexander. 2009. "Vertical Economies of Scope in Dairy Farming." Journal of Agricultural and Food Industrial Organization 7:article 8.

National Research Council. 2007. “Methods for Analysis of Complex Surveys. Chapter 7.” In Understanding American Agriculture: Challenges for the Agricultural Resource Management Survey. Washington, DC: National Academy of Sciences. Available at http://www.nap.edu/cata$\log / 11990 . \mathrm{html}$.

Panzar, J.C., and R.D. Willig. 1975. Economies of Scale and Economies of Scope in Multi-Output Production. Economics Discussion Paper 33. Bell Labs.

Panzar, J.C., and R.D. Willig. 1977. “Economies of Scale in Multi-Output Production." Quarterly Journal of Economics 91 (3):431-493.

Panzar, J.C., and R.D. Willig. 1981. “Economies of Scope.” American Economic Review 71 (2):268-272.

U. S. Department of Agriculture, Economic Research Service. 2009. ARMS Global Documentation. Available at: http://www.ers.usda.gov/Data/ARMS/ClobalDocumentation.htm

Wooldridge, J.M. 1999. “Asymptotic Properties of Weighted M-Estimators for Variable Probability Samples.” Econometrica 67 (6):1385-1406. 